\title{
ENSAIOS
}

\section{OHOLISMO NO TREINAMENTO DOS PROFISSIONAIS DE SAÚDE PARA O ATENDIMENTO AO PÚBLICO LGBTQ+}

\author{
The holism in the training of the health professional to provide medical care to the public \\ LGBTQ+
}

Willian Roger Dullius ${ }^{1}$ Larra Barros Martins ${ }^{2}$

Lynn McCleary ${ }^{3}$

O diálogo sobre sexualidade passou a ser adjeto da negatividade no século XVIII, sucedendo o predomínio na perspectiva da heterossexualidade e na configuração familiar do casal (homem e mulher), mais os filhos decorrentes dessa união. Todas as demais diversidades eram negligenciadas ou consideradas proibidas na percepção cultural da época. Falar sobre a sexualidade era considerado pecado e todos os assuntos que envolvessem esse tema deveriam ser banidos do discurso do cotidiano (KELLY, 2013).

Ainda, em pleno século XXI, vivenciamos esta cultura da heteronormatividade, principalmente, em cidades menores; deste modo, pessoas não heterossexuais são consideradas "inferiores" aos outros e vivenciam discriminação diária; a heterossexualidade, muitas vezes, ainda, é vista como um padrão para avaliar as outras sexualidades, em como, uma hierarquia das sexualidades - heterossexualidade ocuparia uma posição superior, aspectos descritores de heterossexismo (BORRILLO, 2010). A discriminação se estende aos ambientes de atendimento na área da saúde, nos quais verifica-se que os próprios profissionais de saúde, infelizmente, ainda

\footnotetext{
${ }^{1}$ Enfermeiro, Mestre em Psicologia pela Faculdade Meridional/IMED e Professor do Curso Técnico em Enfermagem da Escola Estadual de Ensino Médio Cônego João Batista Sorg; Carazinho, RS rogerdullius@gmail.com

${ }^{2}$ Psicóloga, Doutora em Psicologia pela Universidade de São Paulo em cotutela com a Universidad de Sevilla (Espanha), Docente do Programa de Pós-Graduação Stricto Sensu em Psicologia na Faculdade Meridional/IMED. lara.martins@imed.edu.br

${ }^{3}$ Enfermeira, Doutora em Serviço Serviço Social. Docente do Curso de Enfermagem na Brock University. 1812 Sir Isaac Brock Way, East Academic 3 - EA 317, St. Catharines, Ontario, Canada. 1mccleary@brocku.ca
}

Vol. 02, N. 02, Abr. - Jun., 2019 • www.revistas.unilab.edu.br/index.php/rebeh 
cultivam o padrão da heteronormatividade em seu trabalho cotidiano, afetando drasticamente o processo de saúde-doença-cuidado de pessoas não heteronormativas.

O cenário brasileiro em termos de leis proporciona embasamentos para o acesso à saúde decretos para as pessoas LGBTQ+ (REIDEL, 2018). Por mais que haja leis que assegurem o acesso humanizado ao sistema público de saúde para as pessoas LGBTQ+; a legislação do sistema de saúde embasa uma assistência humanizado em todos os momentos que seja requisitado pelo profissional-usuário, permeando o acolhimento, a gestão participativa, a cogestão da assistência, a ambiência, a clinica ampliada e compartilhada com os demais profissionais da rede de assistência e a defesa dos direitos dos usuários do sistema e dos trabalhadores que estão inseridos nele (BRASIL, 2019). Por mais que as bases teóricas guiem a assistência para uma assistência que se almeje, verifica-se que ainda existem obstáculos ao mesmo como, por exemplo, o diagnóstico médico de "disforia de gênero" permanece no guia de diagnósticos; há longos períodos de tempo de espera para obter a oportunidade de consultar com um médico endocrinologista por parte das pessoas transexuais, levando-as a realizarem, em muitos casos, a automedicação da hormonioterapia - processo que proporciona agravos de saúde, uma vez que a dosagem de hormônios não é controlada conforme a necessidade do indivíduo (REIDEL, 2018).

Quanto ao contexto cultural brasileiro, continua-se a marginalizar pessoas não heteronormativas, discriminando-as e rotulando-as como "seres" doentes e que espalham doenças sexuais para a população. Esse processo de rotulação evidencia drasticamente o abismo da falta de informação das pessoas, bem como, a negação das pessoas transexuais, pois, no geral, a genitália permanece sendo um meio de definir o sexo biológico de um ser humano para a maioria das pessoas (LEMOS, 2018). O mesmo é reproduzido no setor de saúde, já que por mais que os profissionais de saúde relatem que almejam a igualdade no atendimento ao público, verifica-se que o atendimento a pessoas não heterossexuais é diferenciado, por não haver o respeito em utilizar o nome social no atendimento ao cliente ou por haver comportamento de discriminação no atendimento ao indivíduo, como, por exemplo, brincadeiras inadequadas, olhar discriminatório, tom de diálogo inadequado ou diálogo sem contato visual, dentre outros (ASH, MACKERETH, 
2013; MATHARU et al., 2012; TRAVERS et al., 2010), além de haver locais específicos para atender pessoas LGBTQ+.

Questionamentos devem ser feitos sobre esses locais específicos para atender pessoas

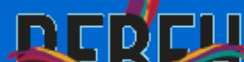

LGBTQ+ no sistema de saúde brasileiro, fato que contrapõe a normativa que prevê a igualdade de âcesso ao atendimento médico/sanitário. Então, por que se faz necessário haver locais específicos para atender o público LGBTQ+, se todos devem ser atendidos igualmente? Isso demonstra o quanto ainda há discriminação, embora contrarie o que está descrito nas legislações e defesas das oportunidades e igualdades ao público LGBTQ+. Por traz da escrita ou dos discursos, ainda, permanece o preconceito e a discriminação.

Na pesquisa de Mahdi et al. (2014), os profissionais de enfermagem obtiveram um escore alto de preconceito quanto ao atendimento do público LGBTQ+. Estes profissionais estão em contato direto com pessoas que requerem cuidados, portanto, não deveriam apresentar qualquer tipo de discriminação, uma vez que, se isso acontece, o processo de proporcionar assistência estará fragmentado para ambos (cliente-profissional). Logo, os enfermeiros devem "abraçar" o arco-íris e humanizar o cuidado a todos, prestando atendimento especializado, competente, bem como humano e de maneira holística a todas as formas de orientação sexual (HARRELL, SASSER, 2017). Somos todos iguais, portanto, o acesso ao sistema de saúde deve ser igualitário para todos, sem exceções, independente da orientação sexual, não necessitando de locais específicos para diferenciar o atendimento ao público, porém deve-se respeitar o principio doutrinário da equidade (“dar mais a quem mais necessite") do sistema para que haja uma assistência adequada ao usuário.

Ainda, sobre a discriminação existente em nosso contexto cultural, em 2017, segundo dados de Mott et al. (2017), um total de 445 pessoas LGBTQ+ faleceram; deste total, 387 indivíduos foram vítimas de assassinatos e 58 indivíduos morreram por suicídio - estes números provavelmente sejam ainda maiores, uma vez que os dados foram obtidos apenas em uma parte do Brasil e outros tantos não são contabilizados. Ao verificar anualmente esse tipo de dados, que revelam a violência contra o coletivo LGBTQ+, evidencia-se que ano após ano os homicídios encontram-se em ascensão. A violência expressa em estatística junto à legislação brasileira para o suporte e auxílio às pessoas não heterossexuais contradizem a realidade. Claramente, a educação (mídia, escolar e educação continuada dos profissionais de saúde) seria uma alternativa urgente tanto para a população brasileira em geral, como na formação e qualificação dos profissionais de saúde, para que haja qualidade no atendimento às pessoas. A homofobia somente deixará de 
predominar se houver educação sobre as múltiplas possibilidades e diversidade sexuais, e não apenas centrar-se na heteronormatividade.

No que diz respeito aos treinamentos ou à educação continuada oferecidos aos profissionais Saúde Integral para Lésbicas, Gays, Bissexuais, Travestis e Transexuais” para que os profissionais se atualizem sobre a política nacional para o público LGBTQ+. Ressalta-se que o referido curso é disponibilizado gratuitamente e de adesão voluntária dos profissionais de saúde. Uma questão se apresenta: será que os profissionais de saúde que desempenham práticas preconceituosas em seu ambiente de trabalho realizam este curso para deixar de exercitar atos discriminatórios no local de trabalho?.

Nos estudos que evidenciam a necessidade de treinamento para os profissionais de saúde para realizarem atendimento ao público LGBTQ+, proporcionando aos mesmos conhecimentos sobre os termos existentes no "guarda-chuva" da diversidade, o que enfatiza o acolhimento humanizado ao prestar assistência ao cliente, resultam positivamente no processo saúde-doençaassistência para ambos. Diferentes treinamentos, por mais curtos que sejam, proporcionam efeitos positivos para os profissionais de saúde e repercutem satisfatoriamente para o público na assistência (PELTS, GALAMBOS, 2017; POTEAT et al., 2017). Essas evidências indicam que a capacitação incide positivamente nos resultados do serviço prestado pelos profissionais de saúde aos clientes, decorrente do processo de ensino proporcionado a estes profissionais. Ressalta-se que enquanto houver discriminação dos profissionais de saúde com o público no contexto geral, se faz necessário haver treinamento, uma vez que o preconceito só deixará de existir quando houver compreensão do assunto pelos profissionais de saúde.

O ensino da diversidade nas universidades não se encontra na grande maioria dos currículos dos cursos de graduação da área da saúde, fato que enfatiza a lacuna de conhecimento para a assistência adequada ao público LGBTQ+, indicando a necessidade de capacitações para esses profissionais. A adesão de conteúdos para a assistência humanizada ao público LGBTQ+ em suas vidas acadêmicas proporcionaria aos estudantes, futuros profissionais de saúde, um "open-mind" da graduação para a vida profissional. Ainda, estudos apontam a importância de inserir no currículo da graduação disciplinas sobre o cuidado integral ao público LGBTQ+ para que haja um processo de humanização do mesmo (CARABEZ et al., 2015; MÜLLER, 2013; TALAN et al., 2017). 
As políticas públicas para a comunidade LGBTQ+ asseguram diversos direitos ao público, porém os mesmos não são de fato garantidos, considerando-se toda a abrangência da sociedade brasileira, havendo brechas entre a realidade existente, o público LGBTQ+ brasileiro e a parte burocrático-prática. A violência existente para as pessoas que se consideram não heteronormativas êvidencia a necessidade de educação para a população brasileira, bem como, a inserção de conteúdos no âmbito da graduação nas áreas de saúde sobre a diversidade, e também na educação continuada para os profissionais de saúde que proporcionam cuidados - para que estes sejam apresentados de forma humanizada e não pejorativa, dirimindo a discriminação existente. Por fim, espera-se que o contexto brasileiro deixe de proporcionar o atendimento às pessoas LGBTQ+ em uma unidade de saúde específica, mas proporcione o cuidado humanizado em qualquer unidade de saúde em todo o território nacional, uma vez que a legislação que rege o SUS garante o atendimento integral e com equidade a qualquer ser humano, promovendo uma resolutiva com igualdade na assistência; que os gestores promovam educação continuada (treinamentos presenciais e on-line) aos profissionais com diferentes metodologias de aprendizagem para que promova sensibilização e educação dos profissionais, uma vez que, somos todos seres humanos independente da orientação sexual de cada um.

\section{REFERÊNCIAS}

ASH, Marcia; MACKERETH, Catherine. "Assessing the mental health and wellbeing of the lesbian, gay, bisexual and transgender population." Community Pract. 86(3): 24-27, março. 2013.

BRASIL, Ministerio da Saúde. Política Nacional de Humanização - HumanizaSUS. Disponivel em: $\quad$ http://www.saude.gov.br/saude-de-a-z/projeto-lean-nas-emergencias/693-acoes-eprogramas/40038-humanizasus Acesso em 20 de junho de 2019.

BORRILLO, Daniel. Homofobia: história e critica de um preconceito. [tradução de Guilherme João de Freitas Teixeira]. Belo Horizonte: Autêntica Editora, 2010.

CARABEZ, Rebecca; PELLEGRINI, Marion; MANKOVITZ, Andrea; ELIASON, Mickey; CIANO, Mark; SCOTT, Megan. "“Never in All My Years. . .": Nurses' Education About LGBT Health." Journal of Professional Nursing. 31(4): 323-329, julho-agosto. 2015.

HARRELL, Bradley; SASSER, Jason. Guest Editorial: "Sexual and gender minority health: Nursing's overdue coming out." International Journal of Nursing Studies. Janeiro. ISSN: 
0020-7489. 2017.

KELLY, Mark. Foucault's 'History of Sexuality Volume I, The Will to Knowledge' [electronic resource] : An Edinburgh Philosophical Guide. Edinburgh : Edinburgh University Press. 2013. de Estudos da Homocultura, 1(1) [on-line]. 2018. Disponível em:

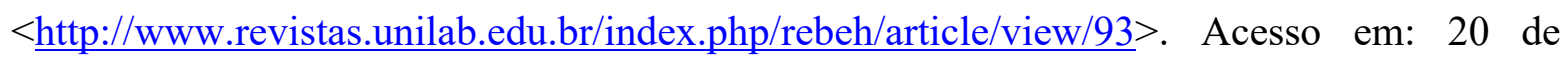
janeiro de 2018.

MAHDI, Inas; JEVERTSON, Jenn; SCHRADER, Ronald; NELSON, Anna; RAMOS, Mary. "Survey of New Mexico School Health." Journal of School Health. 84(1): 18-24, dezembro. 2014.

MATHARU, Kabir; KRAVITZ, Richard; MCMAHON, Graham; WILSON, Machelle; FITZGERALD, Faith. "Medical students attitudes toward gay men." BMC Medical Education. 12(1): 71, agosto. 2012.

MOTT, Luiz; MICHELS, Eduardo, PAULINHO; COLABORADORES. Relatório 2017: Pessoas LGBT Mortas no Brasil. Grupo Gay da Bahia, 1 [on-line]. 2017. Disponível: $<$ https://homofobiamata.files.wordpress.com/2017/12/relatorio-2081.pdf $>$ Acesso em: 18 de janeiro de 2018.

MÜLLER, Alexandra. "Teaching lesbian, gay , bisexual and transgender health in a South African health sciences faculty: addressing the gap." BMC Medical Education. 2013.

PELTS, Michael; GALAMBOS, Collen. "Intergroup Contact: Using Storytelling to Increase Awareness of Lesbian and Gay Older Adults in Long-Term Care Settings." Journal of Gerontological Social Work. 60(6-7): 587-604, junho. 2017.

POTEAT, Tonia; PARK, Chulwoo; SOLARES, Diego; WILLIAMS, John; WOLF, R Cameron; METHENY, Noah; VAZZANO, Andrea; DENT, Juan; GIBBS, Ashley, NONYANE, Bareng; TOIV, Nora. "Changing hearts and minds: Results from a multi-country gender and sexual diversity training." PLoS ONE. 12(9): 1-16, setembro. 2017.

REIDEL, Marina. Reflexões sobre as políticas públicas brasileiras LGBT. Rebeh - Revista Brasileira de Estudos da Homocultura, 1(1) [on-line]. 2018. Disponível em:

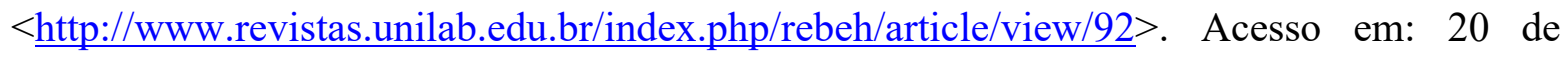
janeiro de 2018 .

Vol. 02, N. 02, Abr. - Jun., 2019 • www.revistas.unilab.edu.br/index.php/rebeh 
TALAN, Ali; DRAKE, Carolyn; GLICK, Jennifer; CLAIBORN, Camilla; SEAL, David. "Sexual and Gender Minority Health Curricula and Institutional Support Services at U.S. Schools of Public Health." Journal of Homosexuality. 64(10): 1350-1367, maio. 2017. gay, bisexual, and transgender youth." Canadian Journal of Human Sexuality. 19(4): 191198, fevereiro. 2010.

Recebido em: 19/06/2018

Aceito em: 04/06/2019 